\title{
Impairment of the biomechanical compliance of $P$ pili: a novel means of inhibiting uropathogenic bacterial infections?
}

\author{
Jeanna E. Klinth · Jerome S. Pinkner • \\ Scott J. Hultgren • Fredrik Almqvist • \\ Bernt Eric Uhlin · Ove Axner
}

Received: 30 June 2011 / Revised: 25 November 2011/Accepted: 6 December 2011/Published online: 12 January 2012

(C) The Author(s) 2012. This article is published with open access at Springerlink.com

\begin{abstract}
Gram-negative bacteria often initiate their colonization by use of extended attachment organelles, so called pili. When exposed to force, the rod of helix-like pili has been found to be highly extendable, mainly attributed to uncoiling and recoiling of its quaternary structure. This provides the bacteria with the ability to redistribute an external force among a multitude of pili, which enables them to withstand strong rinsing flows, which, in turn, facilitates adherence and colonization processes critical to virulence. Thus, pili fibers are possible targets for novel antibacterial agents. By use of a substance that
\end{abstract}

\section{J. E. Klinth $(\varangle) \cdot$ O. Axner}

Department of Physics, Umeå University,

90187 Umeå, Sweden

e-mail: jeanna.klinth@physics.umu.se

J. E. Klinth · F. Almqvist - B. E. Uhlin · O. Axner

Umeå Centre for Microbial Research (UCMR),

Umeå University, 90187 Umeå, Sweden

J. E. Klinth · B. E. Uhlin

Department of Molecular Biology, Umeå University,

90187 Umeå, Sweden

\section{J. E. Klinth · B. E. Uhlin}

Laboratory for Molecular Infection Medicine Sweden (MIMS), Umeå University, 90187 Umeå, Sweden

J. E. Klinth · O. Axner

Center for Biomedical Engineering and Physics (CMTF),

Umeå University, 90187 Umeå, Sweden

\section{J. S. Pinkner · S. J. Hultgren}

Department of Molecular Microbiology, Washington University

School of Medicine, St. Louis, MO 63110, USA

F. Almqvist

Department of Chemistry, Umeå University,

90187 Umeå, Sweden compromises compliance of the pili, the ability of bacteria to redistribute external forces can be impaired, so they will no longer be able to resist strong urine flow and thus be removed from the host. It is possible such a substance can serve as an alternative to existing antibiotics in the future or be a part of a multi-drug. In this work we investigated whether it is possible to achieve this by targeting the recoiling process. The test substance was purified PapD. The effect of PapD on the compliance of $\mathrm{P}$ pili was assessed at the single organelle level by use of forcemeasuring optical tweezers. We showed that the recoiling process, and thus the biomechanical compliance, in particular the recoiling process, can be impaired by the presence of PapD. This leads to a new concept in the search for novel drug candidates combating uropathogenic bacterial infections-"coilicides", targeting the subunits of which the pilus rod is composed.

Keywords Bacterial adhesion - Force-measuring optical tweezers · Antimicrobial $\cdot$ Single organelle $\cdot$ Pili recoiling

\section{Introduction}

According to the World Health Organization, resistance to antibiotics is the biggest challenge in drug development. There is a need not for one new antibiotic substance but several, so these can be combined and strengthen the human position in the fight against bacterial resistance (Kaplan and Laing 2004). This necessitates the identification and addressing of new targets in bacteria. Bacterial pathogens have a variety of mechanisms that contribute to their ability to colonize and cause disease in human hosts (Staskawicz et al. 2001). It is well known that the virulence of a microbe, i.e. its ability to infect, is correlated with its ability to adhere 
to tissue, and, in particular, to its capability to withstand forces from rinsing flows (Ofek et al. 2003). Some bacteria mediate adhesion by use of long attachment organelles, also referred to as fimbriae or pili. $\mathrm{P}$ pili, a prototype helix-like pili, are produced by uropathogenic Escherichia coli (UPEC) strains and are predominantly associated with kidney infection (pyelonephritis) (Sauer et al. 2000). The rod of $\mathrm{P}$ pili consists of more than a thousand PapA subunits, assembled into a helical right-handed structure with 3.3 subunits per turn (Gong and Makowski 1992; Bullitt and Makowski 1995), ending in a linear tip structure that anchors the PapG adhesin at the distal end (Jacob-Dubuisson et al. 1993; Kuehn et al. 1992; Striker et al. 1994; Lee et al. 2007; Lindberg et al. 1987). As is further alluded to below, the ability of such attached bacteria to withstand forces caused by rinsing flows is not only given by the properties of the adhesin-receptor interactions, but is also strongly affected by the biomechanical properties of these organelles (Duncan et al. 2005).

It has been found that the compliance of helix-like pili (i.e. their response to force), and thus their ability to assist in the adhesion process, depends strongly on the quaternary structure of the pilus. These pili have an intricate and extraordinary force versus elongation response that consists of a combination of a constant elongation force (in the socalled region II), originating from sequential uncoiling of the helix-like structure, and a sigmoidal pseudo-elastic response (region III), caused by a conformational change of the head-to-tail interaction between the subunits of pili that takes place in a random order (Jass et al. 2004; Fällman et al. 2005; Andersson et al. 2007, 2008; Björnham et al. 2008; Axner et al. 2009). These extraordinary biomechanical properties, primarily those of region II, which enable significant elongation of pili length [more than five times the original length for P pili (Jass et al. 2004)] under a constant force, and the fact that the uncoiling is fully reversible (Fällman et al. 2005), have been regarded as being of special importance to the ability of a piliated bacterium to remain attached to the host tissue (despite being exposed to a substantial external force) by redistributing an external shear force among a multitude of pili (Björnham et al. 2008). Presumably, they are a major reason why the ability of attached bacteria to withstand forces caused by urine flow is strongly affected by the properties of the pili shaft per se (Duncan et al. 2005). This implies that the pilus rod and the tip-associated adhesin are both important in the ability of bacteria to withstand strong rinsing forces (Björnham and Axner 2009).

During recent decades much work has been devoted to understanding the adhesive binding mechanism. For example, fimbrial tip-mediated and shear-dependent adhesion (Le Trong et al. 2010) and a shear-enhanced adhesion mechanism (Whitfield et al. 2010) have been demonstrated.
To prevent bacterial attachment, inhibitors targeting the adhesion process, i.e. carbohydrate derived competitive inhibitors for adhesin-receptor interactions, have been developed (Wellens et al. 2008; Salminen et al. 2007; Ohlsson et al. 2002; Krogfelt et al. 1990). In addition to this ligand-based approach, several bicyclic 2-pyridones, referred to as pilicides, have been rationally designed to prevent pili formation. It has been suggested that pilicides inhibit the chaperone-usher interaction, thus preventing the essential event in which the N-terminus of the usher (a membrane protein involved in the pili assembly) recognizes and binds to incoming chaperone-subunit complexes (Pinkner et al. 2006). These pilicides can efficiently inhibit pili biogenesis without affecting bacterial growth (Åberg et al. 2006; Pinkner et al. 2006; Cegelski et al. 2009; Chorell et al. 2010). In contrast, so far, the pili rod has not been used as a target for antibiotics.

In this work we investigated whether it is possible to affect the biomechanical properties of helix-like pili by using a substance that can bind to an elongated pilus at the single organelle level, primarily compromising the uncoiling-recoiling process. We show, by use of forcemeasuring optical tweezers (FMOT), that the biomechanical compliance of $\mathrm{P}$ pili can be impaired without breaking the backbone of the pilus. Thus, the pili rod can be regarded as a new target for novel drug candidates combating uropathogenic bacterial infections.

\section{Materials and methods}

\section{Culture of bacteria}

The Escherichia coli (E. coli) strain used was HB101/ pPAP5, which is a clone carrying the wild type pap gene cluster from UPEC strain J96 (Lindberg et al. 1984). A typical HB101/pPAP5 piliated cell is shown in Fig. 1a. Because it has previously been found that study of fewer pili per bacterium enhances the ability to capture a single organelle for force measurements, a pilicide, a substituted ringfused 2-pyridone (BibC10, Fig. 1b), referred to as pilicide 1 by Aberg and Almqvist (2007), was used to chemically manipulate the number of pili expressed per bacterial cell. For pilicide concentrations below that required for total inhibition of pili, the bacteria express fewer pili, in a concentration-dependent manner, although with the same biomechanical properties as for untreated bacteria (^̊berg et al. 2007). Bacteria were therefore cultured on trypticase soy agar (TSA; Becton Dickinson, NJ, USA), supplemented with $50 \mu \mathrm{g} / \mathrm{ml}$ carbenicillin (Duchefa Biochemie, Limhamn, Sweden) in the presence of $2.2 \mathrm{mM}$ pilicide at $37^{\circ} \mathrm{C}$ overnight. To remove pilicide possibly present on the surface of the bacteria, the bacteria were washed three times by dilution 

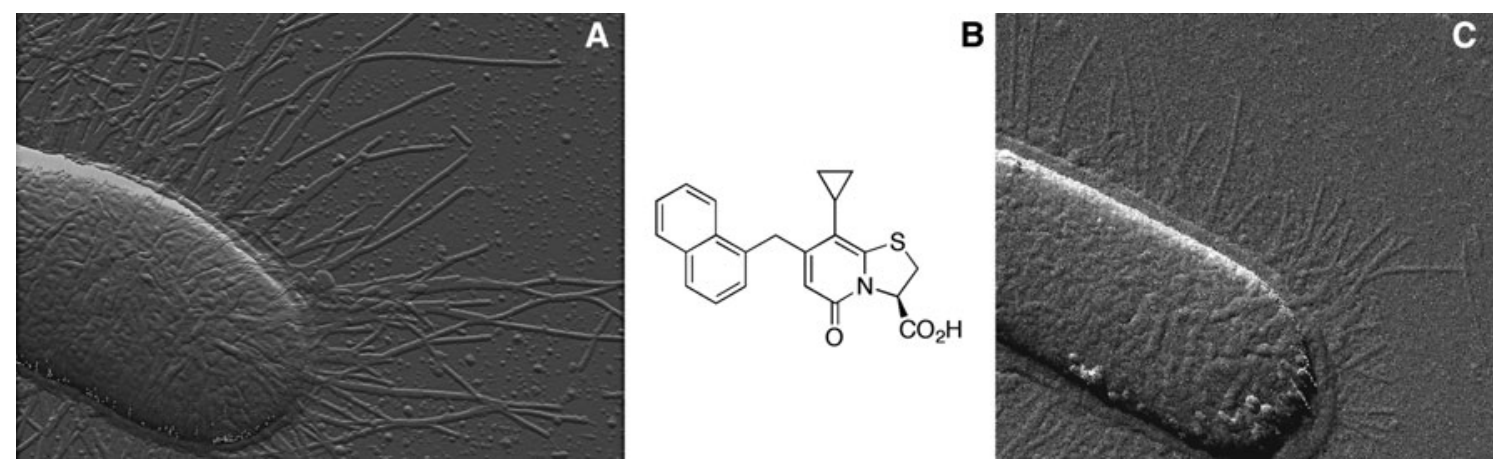

Fig. 1 AFM micrographs of HB101/pPAP5 cells expressing P pili: a bacterium cultured under normal conditions, b chemical structure of pilicide 1, $\mathbf{c}$ bacterium cultured on a plate containing $2.2 \mathrm{mM}$ pilicide

(20,000-fold) with Dulbecco's phosphate-buffered saline (DPBS, $10 \mathrm{mM}$ phosphate, $130 \mathrm{mM} \mathrm{NaCl}$, pH 7.0, SigmaAldrich, Schnelldorf, Germany) just before use in force measurements. Expression of pili was confirmed by atomicforce microscopy (AFM) imaging as described elsewhere (Åberg and Almqvist 2007). A typical bacterium cultured on a plate containing $2.2 \mathrm{mM}$ pilicide $\mathbf{1}$ is shown in the AFM micrograph in Fig. 1c.

\section{PapD and control proteins}

PapD and FimC, periplasmic chaperones from E. coli, were expressed and purified as described elsewhere (Lindberg et al. 1989). Bovine serum albumin (BSA) and insulin-like growth factor binding protein-5 (IGFBP-5; both from Sigma-Aldrich) were used as controls of the PapD specific inhibitory effect. IGFBP-5 was purchased as a mixture with BSA. These proteins were separated by spinning for $12 \mathrm{~min}$ at $14,000 \times \mathrm{g}$ at room temperature using a Microcon centrifugal filter device (Millipore, Solna, Sweden) in a Hermle Z200 M/H centrifuge. The protein concentration was determined spectrophotometrically at $280 \mathrm{~nm}$. The size and purity of proteins was confirmed by $12.5 \%$ sodium dodecyl sulfate-polyacrylamide gel electrophoresis (SDSPAGE; acrylamide-bis (50:1); BioRad Laboratories, Hercules, CA, USA), stained by PageBlue protein staining solution (Fermentas International, Helsingborg, Sweden).

Force-measurement procedure

Polymeric microspheres $(9.7 \mu \mathrm{m}$, Duke Scientific, Palo Alto, CA, USA) were immobilized by heating a droplet of suspension at $60^{\circ} \mathrm{C}$ for $1 \mathrm{~h}$ on microscope cover slips (VWR, Stockholm, Sweden) and functionalized with $0.01 \%$ poly-Llysine (Sigma-Aldrich, Stockholm, Sweden). On top of these spheres, samples containing bacteria, PapD $(1.4,2.8$ and $11.3 \mu \mathrm{M})$, or control proteins $(2.8 \mu \mathrm{M})$, and $3.0-\mu \mathrm{m}$ polymeric microspheres (Duke Scientific) were applied in a total volume of $10 \mu \mathrm{l}$. A string of high-vacuum grease (Dow
Corning, Midland, MI, USA) around the sample and a second cover slip were used to protect the sample against evaporation. Force measurements were performed by use of optical tweezers, as described elsewhere (Fällman et al. 2004; Jass et al. 2004), at a constant temperature of $25^{\circ} \mathrm{C}$. Briefly, a freefloating bacterium was trapped at low power by use of a focused laser beam and attached to a poly-L-lysine-coated bead fixed on the cover slip. A small bead $(3.0 \mu \mathrm{m})$ was then captured and the trap was calibrated by use of the power spectrum method in order to determine the stiffness of the trap (Fällman et al. 2004). Thereafter, the trapped bead was moved back and forth close to the bacterium until pili attached to it. Data acquisition was started and the piezostage automatically set in motion, at an elongation speed of $0.1 \mu \mathrm{m} / \mathrm{s}$, in order to separate the bacterium from the small bead. If several pili were initially attached to the trapped bead, the separation was repeated so pili detached from the bead until a single pilus remained.

\section{Results and discussion}

FMOT have previously been used for characterization of the biomechanical properties of several different types of pili (Andersson et al. 2006a; Castelain et al. 2009, 2010; Axner et al. 2011), so the compliance of various types of pili is well known. A typical force versus elongation curve for P pili expressed by UPEC bacteria is shown in Fig. 2. As was alluded to in the "Introduction", the data show that a helix-like pilus has a force versus elongation response that can be seen as composed of three regions (Andersson et al. 2008; Jass et al. 2004; Björnham et al. 2008; Axner et al. 2009).

Region I is a short region, of little relevance to this study, in which the entire pilus is elongated elastically with no conformational change. In region II, elongation originating from sequential breaking of the turn-to-turn [TT; previously referred to as layer-to-layer (Andersson et al. 2006b)] interactions of the quaternary structure of the pilus 


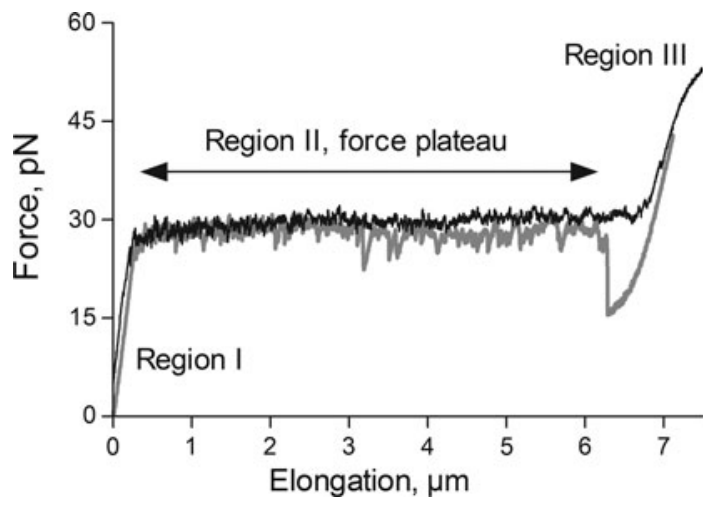

Fig. 2 Force versus elongation response of a single $\mathrm{P}$ pilus elongated at a speed of $0.1 \mu \mathrm{m} / \mathrm{s}$. The characteristic elongation regions I, II, and III are marked

occurs at constant force; this is often referred to as an uncoiling of the pilus rod. The breaking of interactions in this region is sequential, caused by the fact that each turn of the quaternary structure of pili consists of $\sim 3$ subunits, each of which interacts with a corresponding subunit in the neighboring turn. Hence, each turn interacts with the subsequent turn via $\sim 3$ subunits, each of which experiences a fraction $(\sim 1 / 3)$ of the force to which the pilus is exposed. The interaction connecting the outermost unit in the folded part of the rod, on the other hand, experiences the entire force. This implies that, during elongation, breaking of the TT interactions occurs sequentially, which gives rise to a force plateau. For sufficiently low elongation velocities, $\mathrm{P}$ pili have been found to uncoil at a force of $28 \mathrm{pN}$ (Jass et al. 2004; Fällman et al. 2005). For higher velocities, above the so called corner frequency, the uncoiling force increases logarithmically with elongation velocity. Moreover, inasmuch as each TT interaction can open and close a number of times, uncoiling of the helix-like structure has been found to be fully reversible, which, in turn, implies that the pili can rapidly and automatically contract after being unfolded by an external force (Fällman et al. 2005). As was alluded to above, these unique biomechanical properties [together with the fact that the uncoiling process of the rod is assumed to reduce the persistence length of the pili substantially, from being similar to the length of the pili, as demonstrated for type 3 pili of Klebsiella pneumoniae (Chen et al. 2011), to a fraction of it] provide bacteria with extraordinary ability to redistribute an external shear force along several attachment organelles in such a way that no single pilus will experience a substantially greater force than the others; this is beneficial for the ability of a bacterium to sustain substantial rinsing flows.

To investigate the possibility of compromising the biomechanical properties of $\mathrm{P}$ pili, primarily by reducing the force within region II of the force versus elongation curve, we used PapD, the chaperone involved in the biogenesis of
$\mathrm{P}$ pili in vivo, as a test substance. The mechanism of assembly of different types of pili has been well studied (Vetsch et al. 2006; Sauer et al. 1999; Remaut et al. 2006; Rose et al. 2008), and it is known that PapD is responsible for folding of the subunits and for their transport to the usher for assembly of P pili (Barnhart et al. 2000; Bann et al. 2004; Vetsch et al. 2004). During this process, a growing pilus fiber transiently displaces the chaperone PapD. Thus, in the formed pili the binding site of PapD to pili subunits, in what is known from the donor-strand exchange mechanism, is already occupied by the neighboring subunit. However, the crystal structure of a protein complex consisting of two PapA molecules interacting with each other via donor-strand complementation suggests that the PapD molecule can still interact with this type of complex (Verger et al. 2007). An illustration of this structure [PDB ID 2UY6; Verger et al. (2007)] is given in Fig. 3.

The donor-strand complemented PapA subunit is drawn in purple and referred to as "dscPapA". The Nte of this unit is inserted into the donor-strand exchanged PapA subunit, which, according to the donor-strand complementation mechanism, is referred to as "dsePapA", which is drawn in green. Beside the well-documented donorstrand complementation between the two PapA subunits, an additional presumptive interaction has been observed in the PapA/PapA/PapD complex. The C-terminal $\beta$-strand of dscPapA and the F- $\beta$-strand of the PapD [amino acids 107-113 (Holmgren and Branden 1989)] are located in close proximity and can probably interact with each other (indicated by black arrows in Fig. 3). Possible interaction

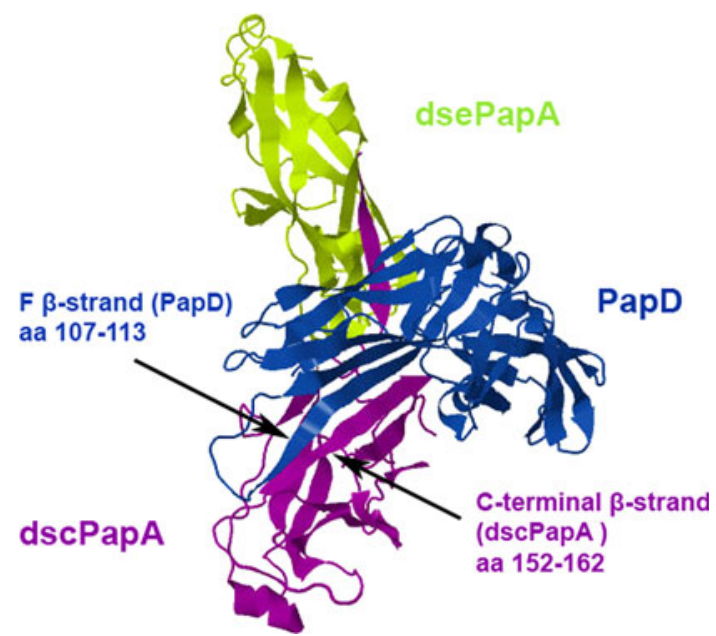

Fig. 3 Overall 3D structure of the PapD/PapA/PapA complex (PDB ID 2UY6): PapD (blue), donor-strand complemented (dsc) PapA (purple), and donor-strand exchanged (dce) PapA (green) are shown in ribbon representation with $\beta$-stands as arrows and $\alpha$-helixes indicated as cylinders. The F- $\beta$-stand of PapD (amino acids 107-113) is indicated by an arrow, as is the C-terminal $\beta$-stand of dscPapA (amino acids 152-162) 
with PapA subunits in the pili rod led to the choice of PapD as the test molecule for this proof-of-principle demonstration of compromise of the biomechanical properties of the pili rod in this work.

As was mentioned above, and as is illustrated in Fig. 2, helix-like pili have a unique and complex force versus elongation response. Normally, a single pilus has a characteristic force plateau in the force versus elongation response (region II) that is flat and repeatable (which originates from sequential uncoiling of the TT interactions in the helix), whereas region III has a sigmoidal shape (which originates from entropy-driven transitions of the head-to-tail bonds opening and closing in random order) (Jass et al. 2004; Fällman et al. 2005; Andersson et al. 2006b, 2007). During retraction, and for sufficiently low elongation and retraction speeds, the response is fully reversible [with the exception of a dip in the transition from region III to II, which is considered to be caused by the lack of a nucleation kernel for formation of the first turn of the quaternary structure during contraction (Axner et al. 2006a, 2009; Lugmaier et al. 2008)].

To assess the effect of PapD on the compliance of the pilus rod, force versus elongation data were collected from eight series of seven replicate elongations and retractions of $\mathrm{P}$ pili in the presence of different concentrations of PapD and control proteins. It was found that in the presence of PapD, the force versus elongation data and the contraction response of $\mathrm{P}$ pili were altered markedly. First, the recoiling forces of $\mathrm{P}$ pili were reduced. As can be seen in Fig. 4, which shows a typical force versus contraction response after the first elongation in the presence of PapD

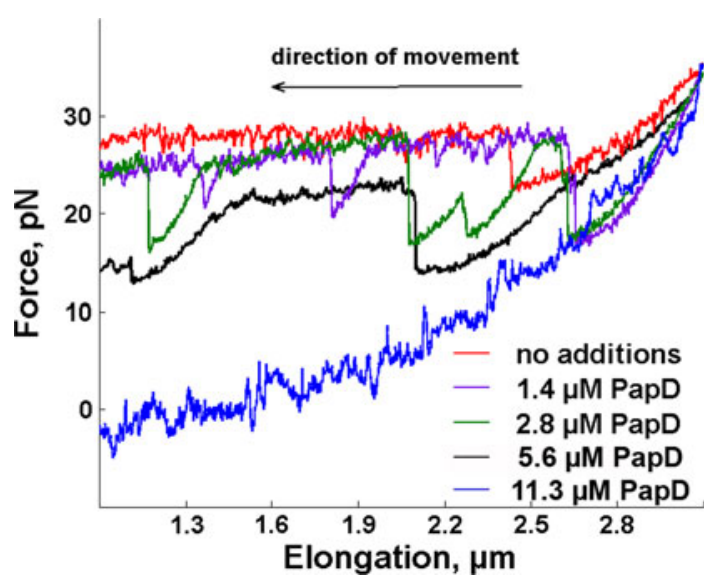

Fig. 4 Transition from region III to II during retraction of a single P pilus in the presence of PapD at different concentrations. In samples with no or a low concentration of PapD, contraction from an elongation of approximately $2.7 \mu \mathrm{m}$ takes place in region II, indicating recoiling, whereas in the sample with $11.3 \mu \mathrm{M}$ PapD, the force decreases towards zero monotonically (which is reached for an elongation of approximately $1.6 \mu \mathrm{m}$ ), indicating no recoiling at three different concentrations, the recoiling forces of $\mathrm{P}$ pili at $1.4 \mu \mathrm{M}$ (violet line) and $2.8 \mu \mathrm{M}$ (green line) of PapD were slightly lower than when no PapD was present (red line) and contained a number of recurring dips.

When a higher concentration of PapD was used (5.6 $\mu \mathrm{M}$, black line, and $11.3 \mu \mathrm{M}$, blue line) the recoiling force dropped drastically. At 11.3 $\mu \mathrm{M}$ PapD the force went monotonically to zero with no characteristic plateau. At 5.6 $\mu \mathrm{M}$ PapD did not completely impair the recoiling of $\mathrm{P}$ pili, but the recoiling force was lower than for additions of 1.4 and $2.8 \mu \mathrm{M}$ PapD. Numerical analysis of the recoiling process during the first half of the plateau in region II (from 2.7 to $1.2 \mu \mathrm{m}$ in Fig. 4) resulted in recoiling forces of $29 \pm 0.7,25 \pm 0.8,23 \pm 1.3,17 \pm 1.4$, and $5.5 \pm 2.2 \mathrm{pN}$ for $0,1.4,2.8,5.6$, and $11.3 \mu \mathrm{M}$ PapD, respectively (expressed as the mean \pm standard error of the mean (SEM), $n=8$ ). This indicates that PapD significantly affects the retraction properties of the rod, suggesting that PapD interacts with PapA subunits in the uncoiled pili by inhibiting the ability of the latter to form TT interactions, thus preventing the pili from recoiling and contracting. This implies that in the presence of the highest PapD concentration the pilus lost virtually all of its compliance.

Also the uncoiling force for subsequent uncoilings was found to be affected by the presence of PapD. For the lowest PapD concentrations, the uncoiling force decreased with the number of elongations. Figure 5a shows seven repeated uncoilings of the same pilus in the presence of $2.8 \mu \mathrm{M}$ PapD. In addition, from the characteristic appearance (with a plateau) during the first uncoiling (red curve), for repeated elongations, the uncoiling curve gradually deteriorated; the plateau became shorter and the force curve transformed to a sigmoidal shape, as is illustrated by the blue curve (the seventh recoiling).

The results from analysis of the uncoiling force (the force plateau) in the presence of PapD and control proteins and the shortening of the plateau are summarized in Table 1, in which each entry represents the average of eight series of seven uncoiling cycles. Because pili length can vary, the lengths of the force plateaus were normalized to that of the first elongation in each set of measurements. Any normalized length below unity thus indicates shortening of region II.

The sigmoidal shape signifies the occurrence of entropic processes, which indicates that the TT interactions can open and close in a random order. This suggests that consecutive turns in the helical structure of the pilus rod no longer interact with each other via multiple TT interactions per turn, which is the underlying cause of the sequential unfolding of the quaternary structure; it reveals that the turns, instead, interact by a single TT interaction per turn, which then enables opening of the helix-like coil in a random order, caused by blocking of the TT interactions by PapD. 
Fig. 5 a Seven successive elongations of a single $\mathrm{P}$ pilus in the presence of $2.8 \mu \mathrm{M}$ PapD. Whereas the response from the first elongation has the conventional plateau, indicative of sequential uncoiling, a sigmoid like response was observed for subsequent elongations, indicating the presence of entropy, which in turn originates from stochastic (non-sequential) opening of the TT-bonds. b-d Force versus elongation curves for a single $\mathrm{P}$ pilus in the presence of $2.8 \mu \mathrm{m}$ BSA, FimC, and IGFBP-5 respectively. Elongation of the pilus was stopped when the pilus had become fully uncoiled and the elongation had proceeded into region III; this was followed by retraction, giving rise to a recoiling of the pilus. This procedure was repeated seven times on the same pilus
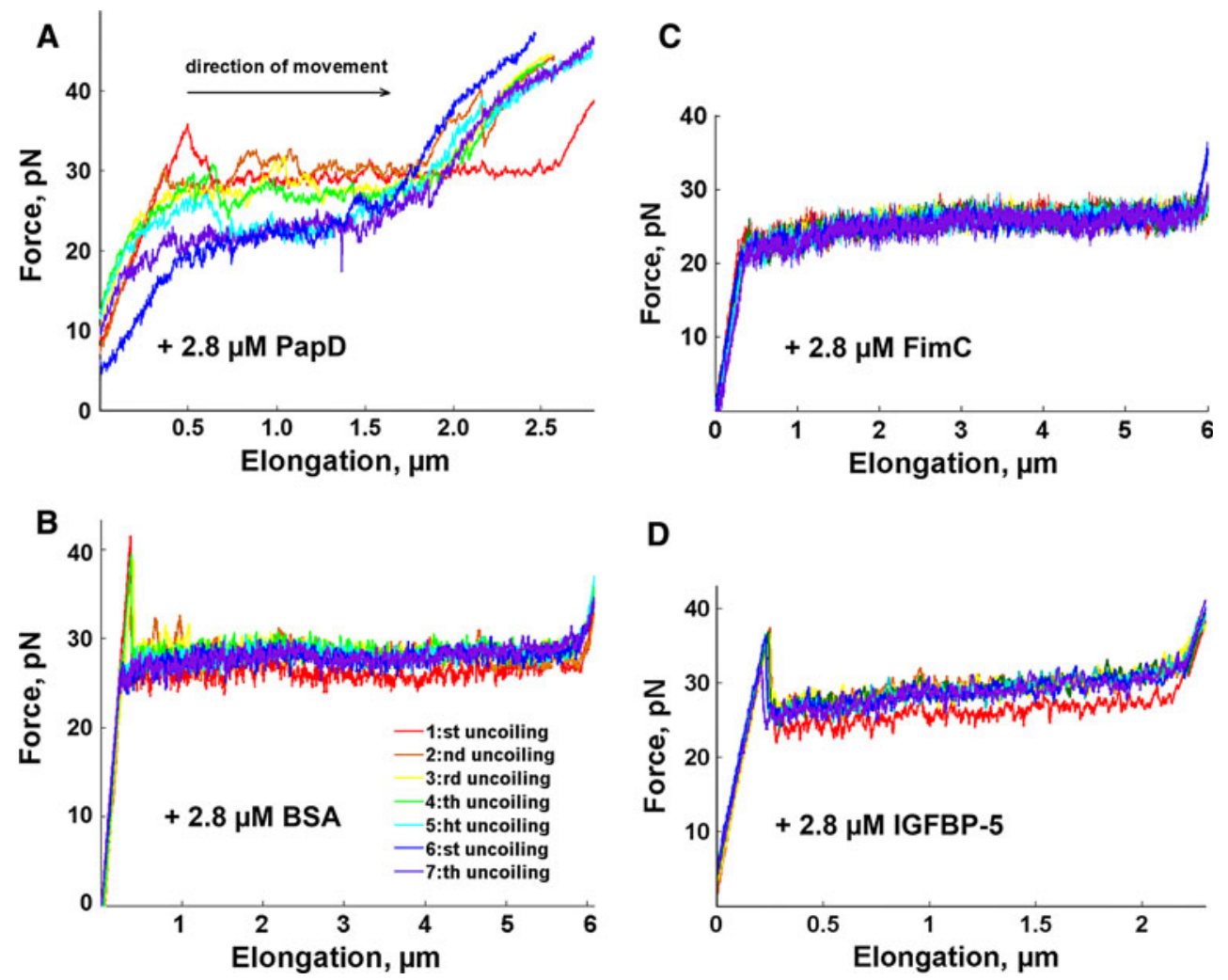

D

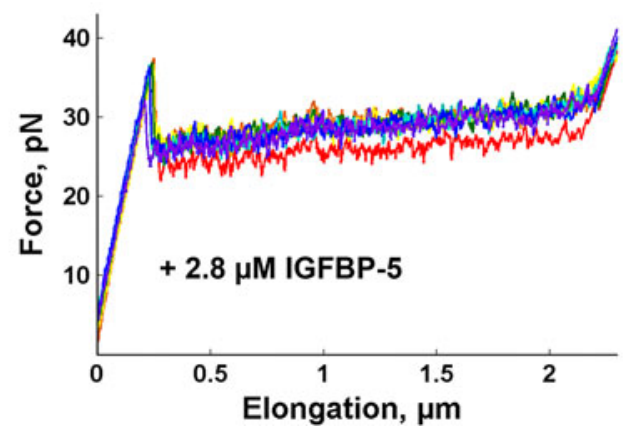

Table 1 Uncoiling forces in the presence of $2.8 \mu \mathrm{M}$ PapD and control proteins during seven repeated elongations, and the relative lengths of the force plateau compared with the length of the plateau during the first elongation cycle $($ mean \pm SEM, $n=8$ )

\begin{tabular}{|c|c|c|c|c|}
\hline \multirow[t]{2}{*}{ Cycle } & \multicolumn{2}{|c|}{ Force $_{\text {plateau }}, \mathrm{pN}$} & \multicolumn{2}{|c|}{ Relative length of the plateau } \\
\hline & PapD & Control & PapD & Control \\
\hline 1 & $28 \pm 1.4$ & $28 \pm 0.3$ & 1 & 1 \\
\hline 2 & $28 \pm 1.8$ & $30 \pm 0.5$ & $0.83 \pm 0.06$ & 1 \\
\hline 3 & $27 \pm 1.8$ & $28 \pm 0.5$ & $0.61 \pm 0.05$ & 1 \\
\hline 4 & $26 \pm 1.8$ & $28 \pm 0.4$ & $0.56 \pm 0.03$ & 1 \\
\hline 5 & $22 \pm 1.1$ & $27 \pm 0.3$ & $0.44 \pm 0.04$ & 1 \\
\hline 6 & $21 \pm 1.4$ & $26 \pm 0.3$ & $0.44 \pm 0.04$ & 1 \\
\hline 7 & $20 \pm 1.4$ & $27 \pm 0.4$ & $0.39 \pm 0.06$ & 1 \\
\hline
\end{tabular}

However, as can be seen from Fig. 5a, the form of the elongation curves is not fully sigmoidal; instead they often have a plateau (or a slightly sloping plateau) in their center. This originates from sequential opening of TT interactions from the part of the pilus in which the consecutive turns still bind by several interactions. The relative length of the plateau, given in Table 1, thus represents how large a fraction of all the turns of the pili can still bind by multiple TT interactions. Conversely, the complementary length, i.e. one minus the relative length, indicates how large a fraction of all the turns bind solely by a single TT interaction. Table 1 indicates that the number of turns that bind solely by a single TT interaction increased as a function of the number of elongation-retraction cycles the pilus was exposed to. After three elongation-retraction cycles (i.e. for the 4th elongation) under the prevailing conditions, approximately half of the turns interacted with their neighboring turns by one TT interaction only. After six elongation-retraction cycles (i.e. for the 7th elongation) most, approximately $60 \%$, of the turns bound solely by one TT interaction. This is in agreement with the assumption that the binding of PapD is cumulative.

A similar change in the shape of the response with the number of elongations was observed during the recoiling process (data not shown). Moreover, the number of dips in the force versus contraction plot was found to increase with the number of elongations. Spontaneous dips in the recoiling curves have been observed previously and attributed to spontaneous miscoilings (Andersson et al. 2007; Åberg et al. 2007). In addition, the effect of repeated 
elongations for low PapD concentrations was comparable that of a single elongation at a higher PapD concentration. This implies that the effect of PapD increased cumulatively with both the concentration of PapD and the number of elongations (the latter is illustrated by the data presented in Table 1).

Furthermore, it was found that PapD only affected linearized (stretched or uncoiled) pili; the first uncoiling curve in a series of elongations was always unaffected by its presence, even after an hour of exposure of unstretched (coiled) pili to PapD. The fact that PapD only bound to PapA units when the rod had been uncoiled indicates that it exclusively binds to the inner parts of the helix-like rod, e.g. as was indicated by Fig. 3. In addition, the cumulative effect indicates that the interaction between PapD and uncoiled $\mathrm{P}$ pili is strong enough for PapD to remain bound to the pili during repeated elongation and retraction cycles.

To verify the recoiling inhibiting effect of PapD, BSA, IGFBP-5, and FimC were used as control substances. The molecular weight of IGFBP-5 is similar to that of PapD but with a secondary structure that is dissimilar to that of PapD. BSA has another secondary structure and a molecular weight that is almost twice that of PapD (Hung et al. 1999). The third control protein, FimC, is a chaperone that is involved in the biogenesis of Type 1 pili in E. coli in the same way as PapD mediates the biogenesis of $\mathrm{P}$ pili. FimC has 50\% amino acid sequence homology with PapD, and the two proteins have similar 3D structures and molecular weights (Jones et al. 1993).

As can be seen by comparison of a single pilus in the presence and absence of $2.8 \mu \mathrm{M}$ control proteins (Fig. 5b-d vs. Fig. 2), it was found that subsequent elongation of $\mathrm{P}$ pili was only very slightly affected by the presence of control proteins. It was, moreover, found that, in the presence of these control proteins, the force versus extension/contraction response of $\mathrm{P}$ pili remained virtually unchanged after the first elongation-in a series of seven repeated elongations (Table 1), the number of dips in the recoiling curves was found to be similar during the first and the last extension cycles-indicating that the effect of control proteins is weaker than that of PapD and not cumulative. A much higher concentration of control proteins $(11.3 \mu \mathrm{M})$ resulted in detectable disturbances of the recoiling process-occasional dips in the recoiling curves resulting in a temporary reduction in uncoiling force. However, the uncoiling force reverted to the normal level during repeated elongations (data not shown).

A schematic illustration of the recoiling inhibitor mechanism from a single bacterium that bind by two helixlike pili is shown in Fig. 6. To mimic the effect of mechanical stress of urine flow in vivo the six horizontal panel pairs (1-6) represent a series of consecutive flow conditions: no flow (panel pair 1), high flow (2), low flow (3), and high flow (illustrated by three panel pairs, 4-6). The high and low flow conditions represent cases where the force to which the bacterium is exposed, $F_{\text {tot }}$, is slightly larger than twice the uncoiling force $\left(F_{\mathrm{uc}}\right)$ and slightly smaller than the uncoiling force, i.e. $F_{\text {tot }}>2 F_{\text {uc }}$ and $F_{\text {tot }}<F_{\text {uc }}$, respectively. The low flow condition (3) can even represent a case with no flow. The first and the second columns of the panels represent pili in the absence and presence of recoiling inhibitor, respectively.

In the absence of flow, the bacterium is initially attached by both pili, neither of them elongated (panels A1 and B1). When the bacterium is exposed to a shear flow, it will rotate (as is indicated in the subsequent panels), so the uppermost pili will be elongated the most. For high flow conditions (panels A2 and B2), both pili will simultaneously elongate in region II. As long as they do so, the two pili will take up the same force, half of the force to which they are exposed, i.e. $F_{\text {upper }}=F_{\text {lower }}=F_{\text {tot }} / 2$, which is a force that the specific adhesin-receptor interaction is presumed to be able to withstand for a substantial time (longer than the force exposure time), so the bacterium will remain attached.

In the absence of a recoiling inhibitor (the first column), when the flow decreases (panel A3) the two pili will retract until both have contracted into region I. During subsequent elongation (panels A4-A6), the two pili will again elongate into region II in a manner similar to that in panel A2, i.e. by sharing the force equally, i.e. $F_{\text {upper }}=F_{\text {lower }}=F_{\text {tot }} / 2$, which is a force the specific adhesin-receptor interaction can withstand for the duration of the force exposure, so the bacterium will stay attached.

When a recoiling inhibitor is present (the second column), on the other hand, the compliance of the pili will be compromised as a result of linearization of the pilus (panel B2). However, there will be no indication of this during the first elongation cycle (because the recoiling inhibitor only attaches to the uncoiled part of the pilus); the reduced compliance will affect the force response solely during subsequent refolding, and more so for the pilus that has been extended the most, which here is assumed to be the upper one (because this has enabled binding of more of the recoiling inhibitor). Under the simplified assumption that the upper pilus loses most of its compliance, as was the case for the highest concentrations of PapD in Fig. 4, whereas the lower one is affected less, the upper pilus will take significantly less force than the lower (in the limiting case when it has lost all of its compliance, it will take no force, whereas the lower one will take all, i.e. $F_{\text {upper }} \approx 0$ whereas $F_{\text {lower }} \approx F_{\text {tot }}$ ) and so will retract less than the lower pilus during the subsequent low flow exposure (panel B3). Under the condition that $F_{\text {tot }}<F_{\text {uc }}$, the lower pilus will retract all the way to region $\mathrm{I}$. When the bacterium is again exposed to a higher flow, the upper pilus will take 
Fig. 6 Schematic illustration of the recoiling inhibitor mechanism on helix-like pili. A bacterium is attached to the host tissue by two identical pili adhering by specific adhesin-receptor bonds. The helixlike pili are depicted as springs, with their length approximately representing their degree of elongation. The arrows indicate the force each pilus sustains

virtually no force (because of its compromised compliance), whereby the lower one will sustain virtually all of the force (panel B4). This implies that the adhesin-receptor bond of the lower pilus will be exposed to a significantly larger force, close to $F_{\text {tot }}\left(>2 F_{\text {uc }}\right)$, which is a force at which the adhesin-receptor bond will rapidly break (panel B5). When this pilus has detached, the upper pilus will be exposed to the entire force, and this also will rapidly become detached (panel B6). Hence, in the presence of a coilicide, the bacterium becomes detached from the host tissue.

Taken together, our findings suggest that the presence of a substance that can bind to the inner parts of an elongated helix-like pilus as a "coilicide" should also affect the attachment lifetime of piliated bacteria exposed to urinary flows. As is schematically indicated in Fig. 6 (by the six pairs of panels that illustrate different consecutive flow conditions), for a bacterium that becomes attached to a host surface with multiple pili (in this case illustrated by two pili), a force that is slightly larger than twice the pili uncoiling force will, in the absence of any coilicide (depicted by the left column of panels), be distributed fairly evenly among the two pili (exactly evenly as long as both pili elongate slowly in region II), also for a multitude of subsequent elongations and retraction cycles (A2-A4). As has been discussed previously (Björnham and Axner 2009), this provides the bacteria with a capability to distribute an external force among a mulitude of pili, which implies they can withstand strong rinsing flows, which, in turn, facilitates adherence and colonization processes critical for virulence. However, as can be seen by a comparison of the two columns of Fig. 6, in which the second column illustrates the response of a bacterium in the presence of a coilicide, the situation changes drastically when the bacterium is exposed to a coilicide. Although the first elongation (panel B2) is identical to that without PapD present (panel A2), subsequent recoiling will be compromised (as is schematically indicated for one of the two pili in panel B3). When a coilicide binds permanently to the inner parts of the helix-like rod, subsequent elongation will be affected. Because one of the pili has lost its compliance, this pilus can no longer withstand substantial force, the other (less compromised, or non-compromised) pilus will be exposed to most of the force (panel B4). This implies that adhesin at the tip of this pilus will be exposed to a

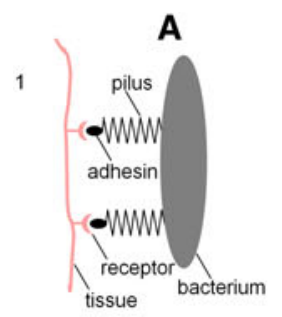

no flow
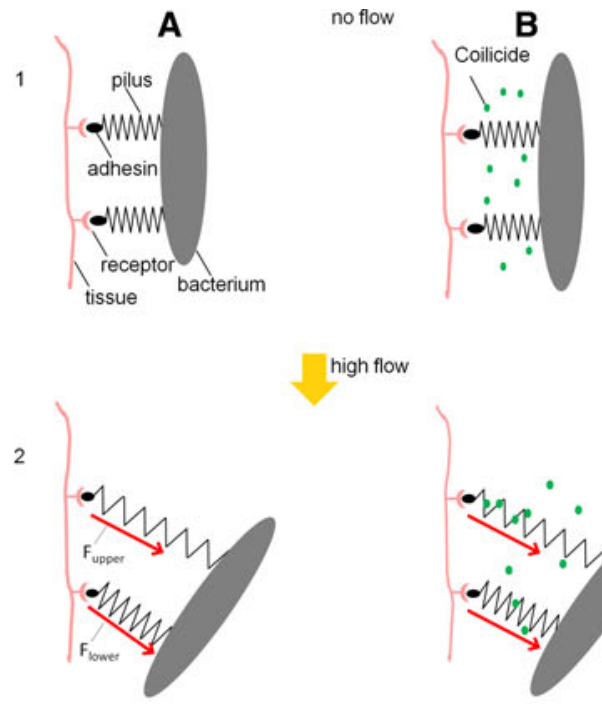

high flow
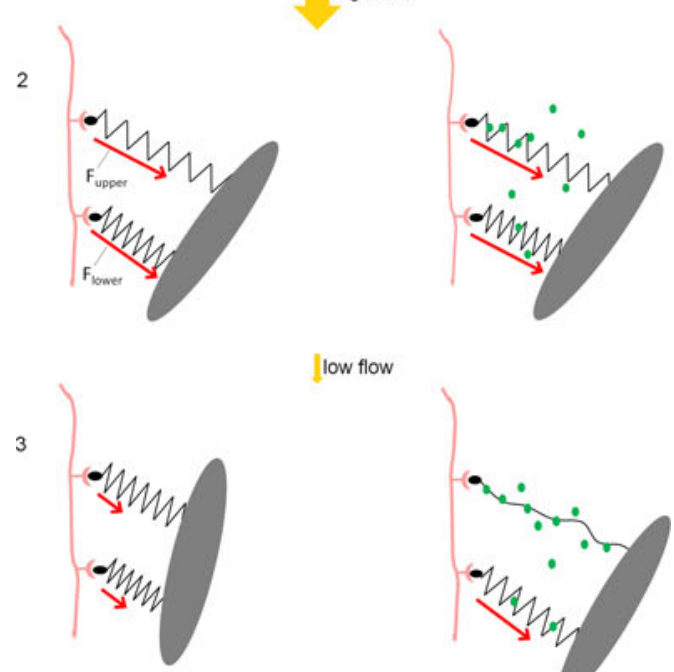

Jlow flow
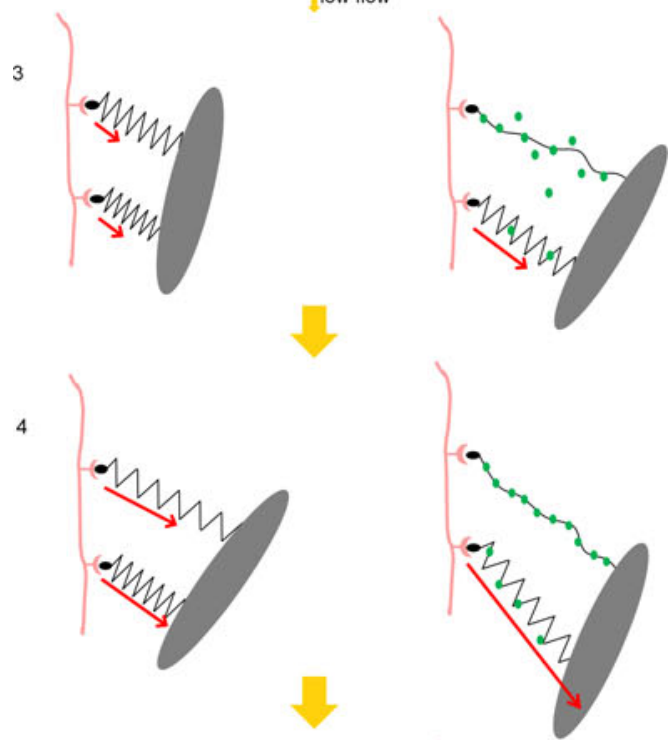

same as 4

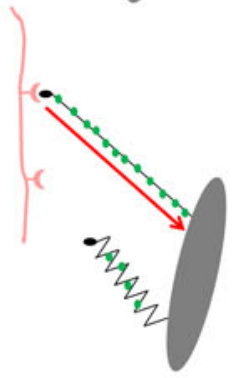

6

same as 4

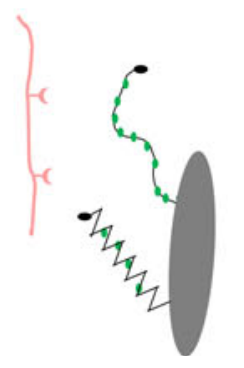


significantly larger force, so it will rapidly become detached from its receptor [under the condition it is attached by a slip bond (Björnham and Axner 2009)], which in turn quickly leads to detachment of the entire bacterium (panels B5-B6).

\section{Conclusions}

In this study, we have investigated whether it is possible to compromise the compliance of helix-like pili by the use of a so-called coilicide. The test substance in this work was PapD, because it has been found to bind to the inner parts of a linearized helix-form $\mathrm{P}$ pili rod. The experiments showed that although the first uncoiling of a given pilus was not affected by the substance investigated, subsequent uncoiling and recoiling (i.e. after the first elongation-andcontraction cycle of the pili) were affected by the presence of PapD. Moreover, use of control substances showed that this effect was obtained specifically in the presence of PapD (and not in the presence of the different tested control proteins). At the highest PapD concentration used the recoiling force dropped to zero, implying the pilus lost all ability to contract, which in turn affected subsequent elongations. At lower PapD concentrations, the plateau during elongations that constitutes region II was transformed into a sigmoidal response, similar to the response of region III, which indicates that elongation in region II was predominantly governed by entropic processes, indicative of a bond opening/closure process that takes place in a randomized order. This behavior suggests that the consecutive turns of subunits no longer form a multitude of parallel interactions. Our results also show that PapD can affect the pilus response even at low concentrations (a single pilus consists of $\sim 1,000$ PapA subunits and, for the PapD concentrations used in this work the estimated number of PapD molecules per single pilus is only a few). All this indicates that the presence of PapD can significantly affect the compliance of $\mathrm{P}$ pili and that it can do so even at low concentrations.

It has thus been demonstrated that the biomechanical properties of helix-like pili can be compromised by a coilicide. It is our expectation that this can be demonstrated also with other types of substance than PapD and that coilicides can be found for other types of pili also; because different kinds of helix-like pili have a similar uncoiling mechanism, it is therefore feasible that one can affect many other types pili in a similar manner.

The results of this study thus provide a new strategy in the search for novel antibacterial drugs-small synthetic molecules that can compromise the biomechanical properties of bacterial pili. In contrast to previously known pilicides that inhibit the chaperone-usher interaction during pili biogenesis, it is proposed the coilicides inhibit the uncoiling/recoiling process of already assembled and surface-located pili. If the ability of bacteria to redistribute external shear forces is compromised, they will no longer be able to resist urine flow, and they will, therefore, presumably be swiftly removed from the host. It is possible that a substance with pili-compliance-compromising ability either can serve as an alternative to existing antibiotics in the future or can be part of a broader strategy, also including substances that can compromise other parts of the adhesion process. This study also demonstrates that FMOT is not only a technique useful for redistribution of micrometersized objects and force measurements, but also for active manipulation of individual macromolecules, serving as an important tool in the search for novel anti-virulence targets, for example the inner parts of helix-like pili.

Acknowledgments We are grateful to Mrs Monica Persson, Dr Magnus Andersson, and Mr Jonas Zakrisson for excellent technical assistance. This work was performed within the Umeå Centre for Microbial Research (UCMR) Linnaeus Program supported from Umeå University and the Swedish Research Council (349-20078673), and Objective 2 North Sweden-EU Structural Fund, and with support also by project grants to FA, BEU, and OA from the Swedish Research Council (621-2010-4730; 621-2009-5720, VR-MH 20103031, K2008-58X-10383, 621-2008-3280), the Kempe Foundations, and by NIH grants to SJH (AI048689 and AI029549).

Open Access This article is distributed under the terms of the Creative Commons Attribution Noncommercial License which permits any noncommercial use, distribution, and reproduction in any medium, provided the original author(s) and source are credited.

\section{References}

Åberg V, Almqvist F (2007) Pilicides—small molecules targeting bacterial virulence. Org Biomol Chem 5(12):1827-1834. doi: $10.1039 / \mathrm{b} 702397 \mathrm{a}$

Åberg V, Sellstedt M, Hedenström M, Pinkner JS, Hultgren SJ, Almqvist F (2006) Design, synthesis and evaluation of peptidomimetics based on substituted bicyclic 2-pyridones-targeting virulence of uropathogenic E coli. Bioorg Med Chem 14(22): $7563-7581$

Åberg V, Fällman E, Axner O, Uhlin BE, Hultgren SJ, Almqvist F (2007) Pilicides regulate pili expression in E. coli without affecting the functional properties of the pilus rod. Mol Biosyst 3(3):214-218

Andersson M, Fällman E, Uhlin BE, Axner O (2006a) Dynamic force spectroscopy of E. coli $\mathrm{P}$ pili. Biophys J 91(7):2717-2725

Andersson M, Fällman E, Uhlin BE, Axner O (2006b) A sticky chain model of the elongation and unfolding of Escherichia coli $\mathrm{P}$ pili under stress. Biophys J 90(5):1521-1534

Andersson M, Uhlin BE, Fällman E (2007) The biomechanical properties of $E$. coli pili for urinary tract attachment reflect the host environment. Biophys J 93(9):3008-3014

Andersson M, Axner O, Almqvist F, Uhlin BE, Fällman E (2008) Physical properties of biopolymers assessed by optical tweezers: analysis of folding and refolding of bacterial pili. Chemphyschem 9(2):221-235 
Axner O, Björnham O, Castelain M, Koutris E, Schedin S, Fällman E, Andersson M (2009) Unraveling the secrets of bacterial adhesion organelles using single-molecule force spectroscopy. In: Gräslund A, Rigler R, Widengren J (eds) Single molecule spectroscopy in chemistry, physics and biology-nobel symposium, vol 96. Chemical Physics, 1st edn. Springer, Berlin, pp 337-362. doi:10.1007/978-3-642-02597-6

Axner O, Andersson M, Björnham O, Castelain M, Klinth J, Koutris E, Schedin S (2011) Assessing bacterial adhesion on an individual adhesin and single pili level using optical tweezers. In: Linke D, Goldman A (eds) Bacterial adhesion, vol 715. Advances in experimental medicine and biology. Springer, Netherlands, pp 301-313. doi:10.1007/978-94-007-0940-9_19

Bann JG, Pinkner JS, Frieden C, Hultgren SJ (2004) Catalysis of protein folding by chaperones in pathogenic bacteria. Proc Natl Acad Sci USA 101(50):17389-17393. doi:10.1073/pnas.0408072101

Barnhart MM, Pinkner JS, Soto GE, Sauer FG, Langermann S, Waksman G, Frieden C, Hultgren SJ (2000) PapD-like chaperones provide the missing information for folding of pilin proteins. Proc Natl Acad Sci USA 97(14):7709-7714. doi: 10.1073/pnas. 130183897130183897

Björnham O, Axner O (2009) Multipili attachment of bacteria with helixlike pili exposed to stress. J Chem Phys 130(23):235102

Björnham O, Axner O, Andersson M (2008) Modeling of the elongation and retraction of Escherichia coli $\mathrm{P}$ pili under strain by Monte Carlo simulations. Eur Biophys J 37(4):381-391

Bullitt E, Makowski L (1995) Structural polymorphism of bacterial adhesion pili. Nature 373(6510):164-167

Castelain M, Koutris E, Andersson M, Wiklund K, Björnham O, Schedin S, Axner O (2009) Characterization of the biomechanical properties of T4 pili expressed by Streptococcus pneumoniae - a comparison between helix-like and open coil-like pili. Chemphyschem 10(9-10):1533-1540

Castelain M, Ehlers S, Klinth JE, Lindberg S, Andersson M, Uhlin BE, Axner O (2010) Fast uncoiling kinetics of F1C pili expressed by uropathogenic Escherichia coli are revealed on a single pilus level using force-measuring optical tweezers. Submited to Eur Biophys J: under final revision

Cegelski L, Pinkner JS, Hammer ND, Cusumano CK, Hung CS, Chorell E, Åberg V, Walker JN, Seed PC, Almqvist F, Chapman MR, Hultgren SJ (2009) Small-molecule inhibitors target Escherichia coli amyloid biogenesis and biofilm formation. Nat Chem Biol 5(12):913-919. doi:10.1038/nchembio.242

Chen FJ, Chan CH, Huang YJ, Liu KL, Peng HL, Chang HY, Liou GG, Yew TR, Liu CH, Hsu KY, Hsu L (2011) Structural and mechanical properties of Klebsiella pneumoniae type 3 fimbriae. J Bacteriol 193(7):1718-1725. doi:10.1128/jb.01395-10

Chorell E, Pinkner JS, Phan G, Edvinsson S, Buelens F, Remaut H, Waksman G, Hultgren SJ, Almqvist F (2010) Design and synthesis of C-2 substituted thiazolo and dihydrothiazolo ringfused 2-pyridones: pilicides with increased antivirulence activity. J Med Chem 53(15):5690-5695. doi:10.1021/jm100470t

Duncan MJ, Mann EL, Cohen MS, Ofek I, Sharon N, Abraham SN (2005) The distinct binding specificities exhibited by enterobacterial type 1 fimbriae are determined by their fimbrial shafts. J Biol Chem 280(45):37707-37716

Fällman E, Schedin S, Jass J, Andersson M, Uhlin BE, Axner O (2004) Optical tweezers based force measurement system for quantitating binding interactions: system design and application for the study of bacterial adhesion. Biosens Bioelectron 19(11): 1429-1437

Fällman E, Schedin S, Jass J, Uhlin BE, Axner O (2005) The unfolding of the $\mathrm{P}$ pili quaternary structure by stretching is reversible, not plastic. EMBO Rep 6(1):52-56

Gong M, Makowski L (1992) Helical structure of P pili from Escherichia coli. Evidence from X-ray fiber diffraction and scanning transmission electron microscopy. J Mol Biol 228(3): $735-742$

Holmgren A, Branden CI (1989) Crystal-structure of chaperone protein PapD reveals an immunoglobulin fold. Nature 342(6247):248-251

Hung DL, Pinkner JS, Knight SD, Hultgren SJ (1999) Structural basis of chaperone self-capping in P pilus biogenesis. Proc Natl Acad Sci USA 96(14):8178-8183

Jacob-Dubuisson F, Heuser J, Dodson K, Normark S, Hultgren S (1993) Initiation of assembly and association of the structural elements of a bacterial pilus depend on two specialized tip proteins. EMBO J 12(3):837-847

Jass J, Schedin S, Fällman E, Ohlsson J, Nilsson UJ, Uhlin BE, Axner $\mathrm{O}$ (2004) Physical properties of Escherichia coli $\mathrm{P}$ pili measured by optical tweezers. Biophys J 87(6):4271-4283

Jones CH, Pinkner JS, Nicholes AV, Slonim LN, Abraham SN, Hultgren SJ (1993) FimC is a periplasmic PapD-like chaperone that directs assembly of type 1 pili in bacteria. Proc Natl Acad Sci USA 90(18):8397-8401

Kaplan W, Laing R (2004) Priority medicines for Europe and the world. WHO, Geneva. Available from: http://whqlibdoc.who. int/hq/2004/WHO_EDM_PAR_2004.7.pdf

Krogfelt KA, Bergmans H, Klemm P (1990) Direct evidence that the FimH protein is the mannose-specific adhesin of Escherichia coli type 1 fimbriae. Infect Immun 58(6):1995-1998

Kuehn MJ, Heuser J, Normark S, Hultgren SJ (1992) P pili in uropathogenic $E$. coli are composite fibres with distinct fibrillar adhesive tips. Nature 356(6366):252-255. doi:10.1038/356252a0

Le Trong I, Aprikian P, Kidd BA, Forero-Shelton M, Tchesnokova V, Rajagopal P, Rodriguez V, Interlandi G, Klevit R, Vogel V, Stenkamp RE, Sokurenko EV, Thomas WE (2010) Structural basis for mechanical force regulation of the adhesin FimH via finger trap-like beta sheet twisting. Cell 141(4):645-655. doi: 10.1016/j.cell.2010.03.038

Lee YM, Dodson KW, Hultgren SJ (2007) Adaptor function of PapF depends on donor strand exchange in P-pilus biogenesis of Escherichia coli. J Bacteriol 189(14):5276-5283. doi:10.1128/ JB.01648-06

Lindberg FP, Lund B, Normark S (1984) Genes of pyelonephritogenic E. coli required for digalactoside-specific agglutination of human cells. EMBO J 3(5):1167-1173

Lindberg F, Lund B, Johansson L, Normark S (1987) Localization of the receptor-binding protein adhesin at the tip of the bacterial pilus. Nature 328(6125):84-87. doi:10.1038/328084a0

Lindberg F, Tennent JM, Hultgren SJ, Lund B, Normark S (1989) PapD, a periplasmic transport protein in P-pilus biogenesis. J Bacteriol 171(11):6052-6058

Lugmaier RA, Schedin S, Kühner F, Benoit M (2008) Dynamic restacking of Escherichia coli P-pili. Eur Biophys J Biophys Lett 37(2):111-120

Ofek I, Hasty DL, Sharon N (2003) Anti-adhesion therapy of bacterial diseases: prospects and problems. FEMS Immunol Med Microbiol 38(3):181-191

Ohlsson J, Jass J, Uhlin BE, Kihlberg J, Nilsson UJ (2002) Discovery of potent inhibitors of PapG adhesins from uropathogenic Escherichia coli through synthesis and evaluation of galabiose derivatives. Chembiochem 3(8):772-779. doi:10.1002/14397633(20020802)3:8<772:AID-CBIC772>3.0.CO;2-8

Pinkner JS, Remaut H, Buelens F, Miller E, Aberg V, Pemberton N, Hedenstrom M, Larsson A, Seed P, Waksman G, Hultgren SJ, Almqvist F (2006) Rationally designed small compounds inhibit pilus biogenesis in uropathogenic bacteria. Proc Natl Acad Sci USA 103(47):17897-17902

Remaut H, Rose RJ, Hannan TJ, Hultgren SJ, Radford SE, Ashcroft AE, Waksman G (2006) Donor-strand exchange in chaperoneassisted pilus assembly proceeds through a concerted beta strand 
displacement mechanism. Mol Cell 22(6):831-842. doi:10.1016/ j.molcel.2006.05.033

Rose RJ, Welsh TS, Waksman G, Ashcroft AE, Radford SE, Paci E (2008) Donor-strand exchange in chaperone-assisted pilus assembly revealed in atomic detail by molecular dynamics. J Mol Biol 375(4):908-919

Salminen A, Loimaranta V, Joosten JA, Khan AS, Hacker J, Pieters RJ, Finne J (2007) Inhibition of P-fimbriated Escherichia coli adhesion by multivalent galabiose derivatives studied by a livebacteria application of surface plasmon resonance. J Antimicrob Chemother 60(3):495-501

Sauer FG, Futterer K, Pinkner JS, Dodson KW, Hultgren SJ, Waksman G (1999) Structural basis of chaperone function and pilus biogenesis. Science 285(5430):1058-1061

Sauer FG, Mulvey MA, Schilling JD, Martinez JJ, Hultgren SJ (2000) Bacterial pili: molecular mechanisms of pathogenesis. Curr Opin Microbiol 3(1):65-72

Staskawicz BJ, Mudgett MB, Dangl JL, Galan JE (2001) Common and contrasting themes of plant and animal diseases. Science 292 (5525):2285-2289. doi:10.1126/science.1062013292/5525/2285

Striker R, Jacob-Dubuisson F, Freiden C, Hultgren SJ (1994) Stable fiber-forming and nonfiber-forming chaperone-subunit complexes in pilus biogenesis. J Biol Chem 269(16):12233-12239
Verger D, Bullitt E, Hultgren SJ, Waksman G (2007) Crystal structure of the P pilus rod subunit PapA. PLoS Pathog 3(5):e73

Vetsch M, Puorger C, Spirig T, Grauschopf U, Weber-Ban EU, Glockshuber R (2004) Pilus chaperones represent a new type of protein-folding catalyst. Nature 431(7006):329-333. doi:10.1038/ nature02891nature02891

Vetsch M, Erilov D, Moliere N, Nishiyama M, Ignatov O, Glockshuber R (2006) Mechanism of fibre assembly through the chaperone-usher pathway. EMBO Rep 7(7):734-738. doi:10.1038/ sj.embor.7400722

Wellens A, Garofalo C, Nguyen H, Van Gerven N, Slattegard R, Hernalsteens JP, Wyns L, Oscarson S, De Greve H, Hultgren S, Bouckaert J (2008) Intervening with urinary tract infections using anti-adhesives based on the crystal structure of the FimHoligomannose-3 complex. PLoS One 3(4):e2040. doi:10.1371/ journal.pone.0002040

Whitfield M, Ghose T, Thomas W (2010) Shear-stabilized rolling behavior of $E$. coli examined with simulations. Biophys $\mathrm{J}$ 99(8):2470-2478. doi:10.1016/j.bpj.2010.08.045 